\title{
Development and Performance Evaluation of a Natural Draft Mixed-Type Solar Dryer for Agricultural Products
}

\author{
Joseph I. Orisaleye $^{1^{*}}$, Mercy Ogbonnaya ${ }^{1}$, Adebayo A. Ogundare ${ }^{1}$, Sikiru O. Ismail ${ }^{1,2}$ \\ 1* Mechanical Engineering Department, University of Lagos, Nigeria. \\ ${ }^{2}$ Mechanical Engineering Department, University of Portsmouth, UK.
}

Received 1 May 2018; accepted 2 November 2018; available online 11 November 2018

\begin{abstract}
Reduced moisture content enhances storage properties of agricultural products and reduces postharvest losses. Effective drying can be achieved using solar dryers in regions with abundant solar radiation. In this study, a natural draft mixed-type solar dryer suitable for rural communities of developing countries was developed. The performance of the solar dryer was also investigated using pepper, okra and tomato. The temperature taken at different points of the drying chamber and the auxiliary collector show that the temperature within the drying chamber is higher than the ambient temperature. The temperature within the drying chamber was also found to depend on the atmospheric conditions. The maximum drying rate was obtained at periods between 1200 and $1400 \mathrm{hrs}$ Nigeria local time during which the temperature within the solar dryer is also maximum. Temperature within the solar dryer reached up to $62^{\circ} \mathrm{C}$. The solar collector efficiency was $52.0 \%$ while the drying efficiency was $21.9 \%$.
\end{abstract}

Keyword: Agricultural products; Mixed-type solar dryer; Moisture content; Natural draft; Temperature.

\section{Introduction}

Post-harvest losses often occur due to inability to properly store agricultural products, which is due, in part, to their high moisture content. This is particularly common in less developed or developing countries. Drying is one of the oldest preservation methods for food and agricultural products with the aim of removing moisture as quickly as possible without seriously affecting the flavour, texture and colour of the food [1]. Whilst traditional sun drying has thrived over time, the safety of dried product is doubtful due to exposure to pests such as flies, birds and rodents. The utilization of a solar dryer could improve storage potential of agricultural products by rapid rate of drying and also prevent dust and other contaminants from settling on the food items, whilst protecting them from pests.

Solar dryers have been classified into passive and active solar dryers depending on the air flow through the dryer. Passive dryers depend on the natural convection of air while the active dryers work on the basis of forced convection. Types of passive dryers include the cabinet type natural circulation solar dryer and the greenhouse type natural circulation solar dryer. Forced convection or active solar dryers utilizes blowers or fans to circulate air in the system. Types of forced convection solar dryers include the cabinet type forced circulation solar dryer, the chamber forced circulation solar dryer and the greenhouse type forced circulation solar dryer. A review of some solar dryer technologies pointed out that natural and forced draft solar dryers are useful to small scale farmers of rural communities of developing countries [2].

Another classification, based on the mode by which the heat derived from solar radiation is utilized, categorises solar dryers into direct, indirect, mixed, and hybrid solar dryers. In direct solar dryers, heat is absorbed directly by the product, through a transparent cover, to cause drying but in the indirect solar dryers, air is heated in a solar collector and then ducted to the drying chamber to dehydrate the product. The mixed solar dryers combine the direct and indirect systems while the hybrid type utilizes some external source of energy in addition to the solar energy $[3,4]$. The mixed mode solar dryers may dry products in less time compared to direct or indirect solar dryers [2].

A mixed mode solar dryer was designed and evaluated using cassava chips which took two days to dry a batch [5]. It was noted that the drying rate varied with the coordinate position of trays. The dryer had a collector efficiency of $40.0 \%$ and energetic efficiency of $34.5 \%$ for 
half drying capacity. Another study evaluated the performance of a constructed mixed mode solar dryer and observed that chimney air speeds was not greatly affected by modifying the design aspects of the dryer [6]. It was also stated that the overall temperatures depended on irradiance and a box-type chimney was more efficient than a collector-type chimney.

A passive solar dryer was developed and evaluated for corn cobs which took 3 days to dry the maize cobs [7]. This was compared to sun-drying which took 6 days to dry the corn cobs. An on-farm forced convection solar dryer for tomato also performed two times faster than open sun drying [8]. The drying efficiency of the developed dryer was $31 \%$ and products had a better appearance. Experimental investigation has also shown that a solar dyer could reduce the moisture content of vegetables from $89.6 \%$ to $13.0 \%$ in 2 days [9]. A seed dryer which attained temperatures up to $47^{\circ} \mathrm{C}$ had considerable advantage over the traditional sundrying method [10].

A small scale direct mode natural convention solar dryer developed for tomato, okra and carrot [11] had drying efficiencies of $21.8 \%, 21.2 \%$ and $25.0 \%$ respectively for tomato, carrot and okra. Sun drying efficiencies for tomato, carrot and okra were 10.6\%, $12.7 \%$ and $15.2 \%$ respectively. An evaluation of the performance of a mixed mode solar dryer for food preservation obtained drying rate and system efficiency of $0.6 \mathrm{~kg} / \mathrm{h}$ and $57.5 \%$ respectively [12].

A natural convection direct solar dryer to dry mango slices was designed assuming a collector efficiency of $30.0 \%$ [13]. A minimum of $16.8 \mathrm{~m}^{2}$ solar collector area was required to dry a batch of $100 \mathrm{~kg}$ sliced mango slices in 20 hours (two days drying period). An integrated passive domestic dryer which operates in the direct mode was developed [14], used to dry pepper and groundnuts and had collector efficiency of $10.0 \%$ and dryer efficiency of $22.0 \%$. An indirect solar dryer was designed which had a thermal efficiency of $13.8 \%$ [15]. The design and performance evaluation of an indirect type solar dryer for banana drying [16] was reported to have a collector efficiency of $31.5 \%$ and a drying efficiency of $22.4 \%$.

In this study, a natural draft mixed-type solar dryer which is suitable for use in remote communities of developing countries was developed. The performance of the solar dryer was evaluated using pepper, tomato and okra which are commonly grown vegetables in the tropics.

\section{Design Considerations for a Mixed Mode Solar Dryer}

\subsection{Quantity of heat required to remove moisture content}

Preliminary experiments to determine the moisture content of acquired agricultural products (tomato, okra and pepper) revealed that the moisture content ranges between 50\% and $95 \%$. For safe storage, it is required that the moisture content of the agricultural products is reduced to $20 \%$ [17]. The dryer is required to dry a mass of $12 \mathrm{~kg}$ of agricultural product. Where $m_{w}$ is the mass of moisture removed from the product and $h_{f g}$ is the specific latent heat of evaporation of water, the heat required for the drying was estimated from Eq. 1:

$$
Q=m_{\mathrm{w}} h_{\mathrm{fg}} .
$$

The mass of moisture removed from the agricultural product is the difference between the initial moisture content, $m_{i}$, of the product before drying and the final moisture content, $m_{f}$, after drying. Taking the initial moisture content as $\psi_{i}$, the final moisture content as $\psi_{f}$ and the mass of the product as $m_{p}$, the mass of moisture content removed from the agricultural product was estimated from Eq. 2:

$$
m_{\mathrm{w}}=m_{\mathrm{i}}-m_{f}=m_{\mathrm{p}}\left(\frac{\psi_{\mathrm{i}}-\psi_{\mathrm{f}}}{100}\right) .
$$

The mass of moisture to be removed from the agricultural product range from $3.6 \mathrm{~kg}$ to 9.0 $\mathrm{kg}$ depending on the agricultural product. The energy required to remove this moisture ranges from 8.7 to $21.0 \mathrm{MJ}$.

\subsection{Collector tilt angle}

The optimum collector tilt angle for maximum collection of incident radiation for all year operation of a collector is the latitude of the site $[18,19]$. The direct and the indirect collectors were inclined by $6.6^{\circ}$ which corresponds to the latitude of Lagos, Nigeria on latitude $6.6^{\circ} \mathrm{N}$. 


\subsection{Design of solar collectors and drying chamber}

Energy Commission of Nigeria (ECN) and United Nations Development Programme (UNDP) [20] have noted that the solar radiation intensity, $I_{\mathrm{c}}$, around the coastal region in Nigeria is about $12.6 \mathrm{MJ} / \mathrm{m}^{2}$-day. Therefore, to achieve energy of $8.7 \mathrm{MJ}$ to $21.0 \mathrm{MJ}$ per day, the area of the collector should range between $0.7 \mathrm{~m}^{2}$ and $1.7 \mathrm{~m}^{2}$.

The dimension of the direct solar collector is $0.6 \mathrm{~m} \times 0.8 \mathrm{~m} \times 0.9 \mathrm{~m}$. The area of the base of the direct collector is of $0.43 \mathrm{~m}^{2}$. The dimension of the indirect solar dryer is $0.6 \mathrm{~m} \times 0.8 \mathrm{~m}$ which gives a collector area of about $0.5 \mathrm{~m}^{2}$. The total collector area, $\mathrm{A}_{\text {collector }}$, is about $0.9 \mathrm{~m}^{2}$ which lies within the range of collector area required for the solar dryer.

The direct and indirect solar collectors had inner surfaces made from aluminium and were painted black to improve the ability to absorb heat. The drying chamber was designed to have three trays made from galvanized wire mesh. The distances between each tray was $200 \mathrm{~mm}$ with the bottom tray being $250 \mathrm{~mm}$ away from the base of the drying chamber. The drying chamber was lagged with plywood and a chimney with a height of $600 \mathrm{~mm}$ was provided for the natural draft solar dryer. The solar dryer developed is shown in Fig. 1.

\subsection{Air flow within the natural convection solar dryer}

The indirect solar collector, which serves as the auxiliary heater, receives air through the inlet and channels the heated air into the drying chamber. The spent air is then discharged through the chimney placed at the upper part of the drying chamber. The natural draft in the dryer is caused by the difference in temperature of the dryer and the ambient temperature.

To determine the velocity of air flowing through the chimney, it is assumed that the temperature, $T$, within the solar dryer reaches $70^{\circ} \mathrm{C}$, the ambient temperature is $30^{\circ} \mathrm{C}$ and the density of air at $0^{\circ} \mathrm{C}, \rho_{o}$, is $1.3 \mathrm{~kg} / \mathrm{m}^{3}$. The air density at any temperature was determined from Eq. 3 [21].

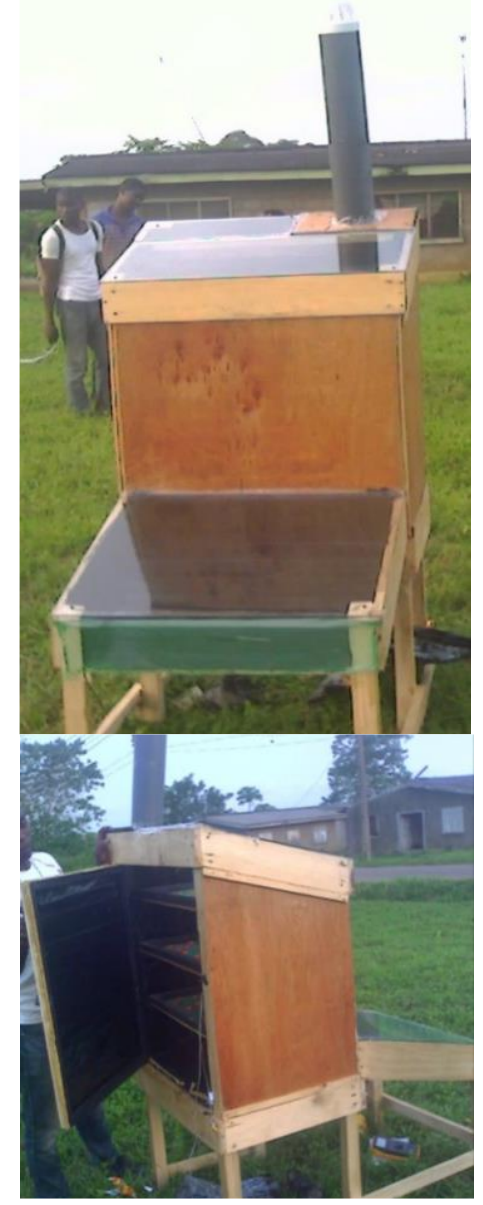

Fig. 1 The mixed-type solar dryer

$$
\rho=\rho_{\mathrm{o}}\left(\frac{273 \mathrm{~K}}{273 \mathrm{~K}+T^{\circ} \mathrm{C}}\right)
$$

The density of air at ambient temperature, $\rho_{a}$, was estimated to be $1.2 \mathrm{~kg} / \mathrm{m}^{3}$ and the density of air at $70^{\circ} \mathrm{C}, \rho_{T}$, was $1.0 \mathrm{~kg} / \mathrm{m}^{3}$. The velocity through the duct was calculated from Eq. 4 which combines the natural draft pressure with the pressure loss in the duct:

$$
\mathrm{v}=\left\{\frac{\left[2 g\left(\rho_{a}-\rho_{T}\right) h\right]}{\left[\frac{\lambda \rho_{\mathrm{T}}}{\mathrm{d}_{\mathrm{h}}}+\zeta \rho_{\mathrm{T}}\right]}\right\}^{\frac{1}{2}}
$$

where $\mathrm{g}$ is the acceleration due to gravity taken as $9.8 \mathrm{~m} / \mathrm{s}^{2}, \mathrm{~h}$ is the height between the air inlet and outlet which is taken as $1.5 \mathrm{~m}, 1$ is the length of the duct taken as $600 \mathrm{~mm}, \lambda$ is the DarcyWeisbach friction coefficient taken as 0.03 using the maximum Reynold's number for 
laminar flow, $d_{h}$ is the duct hydraulic diameter taken as $150 \mathrm{~mm}$ and $\zeta$ is the minor loss coefficient taken as 1 . The velocity of air through the duct was estimated to be $1.9 \mathrm{~m} / \mathrm{s}$. The flow rate, $\dot{\mathrm{V}}$, through the duct is $0.03 \mathrm{~m}^{3} / \mathrm{s}$.

\section{Evaluation of the Solar Dryer}

The solar dryer was evaluated between June and October using tomato, okra and pepper. Every test lasted a daily drying time, $t_{\text {drying }}$, of 10 hours from 0800 - 1800 hours each day. Before drying, okra and pepper were sliced in half but the tomatoes were cut into thin slices.

\subsection{Temperature distribution in the solar dryer}

During evaluation, the temperatures at different points within the solar dryers were measured at intervals of 30 minutes using thermocouples. The temperatures measured included the ambient temperature, $T_{a}$, the temperatures of the auxiliary heater, $T_{b}$, the lower tray, $T_{c}$, the middle tray, $T_{d}$ and the upper tray, $T_{e}$. The positions where the temperatures were taken from are shown in Fig. 2.

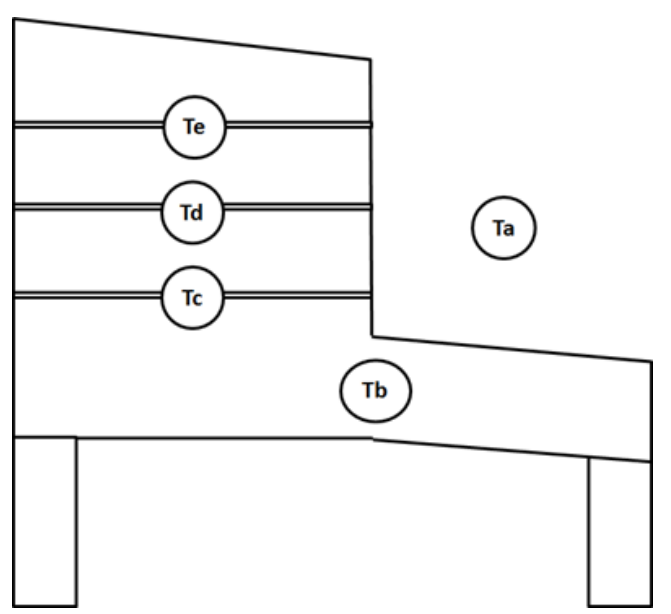

Fig. 2 Schematic drawing showing positions of thermocouples

\subsection{Determination of moisture content of samples}

To determine the moisture content, samples were collected from the trays at an interval of two hours and weighed. To determine the final moisture content, the samples were placed in an oven for one hour with the temperature set to $105^{\circ} \mathrm{C}$. The masses of the samples were measured before and after drying in the oven. The percentage moisture content (\%MC) was determined from Eq. 5:

$$
\% \mathrm{MC}=\frac{\Delta \text { mass of sample }}{\text { initial mass of sample }} \times 100 \text {. }
$$

\subsection{Dryer efficiency}

The dryer efficiency was estimated as the ratio of the energy required to evaporate moisture from the agricultural products to the energy received from the sun through the collectors. The efficiency of the dryer is estimated from Eq. 6:

$$
\eta_{\text {dryer }}=\frac{m_{\mathrm{w}} h_{\mathrm{fg}}}{I_{\mathrm{c}} A_{\text {collector }} \mathrm{t}_{\text {drying }}} .
$$

\subsection{Collector efficiency}

The collector efficiency is the ratio of the total useful energy received by the drying air to the energy received by the collector. The collector efficiency is estimated from Eq. 7:

$$
E=\frac{\rho \dot{V} c_{p} \Delta T}{A_{\text {collector }} \mathrm{I}_{\mathrm{c}}} .
$$

where $\rho_{T}$ is the density of air in the dryer, $\dot{V}$ is the volumetric flow rate, $c_{p}$ is the specific heat capacity of air at constant pressure and $\Delta T$ is the temperature rise in the dryer.

\section{Results and Discussion}

The temperatures measured at various positions of the solar dryer, and compared with the ambient temperature, are shown in Fig. 3. The figure shows the temperatures measured for three different days within the period of testing the solar dryer. The highest temperature measured was at the auxiliary air heater $(\mathrm{Tb})$ which reached up to $73^{\circ} \mathrm{C}$. In the drying chamber, the highest temperature was obtained at the upper tray which reached up to $62^{\circ} \mathrm{C}$ which is a temperature rise of about $30^{\circ} \mathrm{C}$ above the ambient temperature.

It was also noticed that the highest temperatures were recorded between $1200 \mathrm{hrs}$ to $1600 \mathrm{hrs}$. This is clearly observed for day 1 and day 2. Day 3 was, however, mostly cloudy which is indicated by significantly lower 
temperatures compared to previous days. For the middle and lower trays, the temperatures recorded were close but the temperature at the lower tray was lower at most periods than the middle tray.

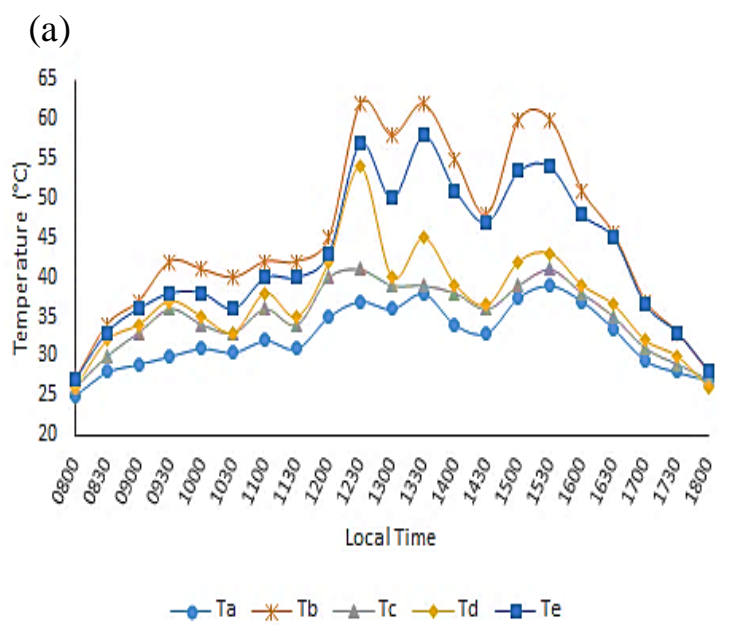

(b)

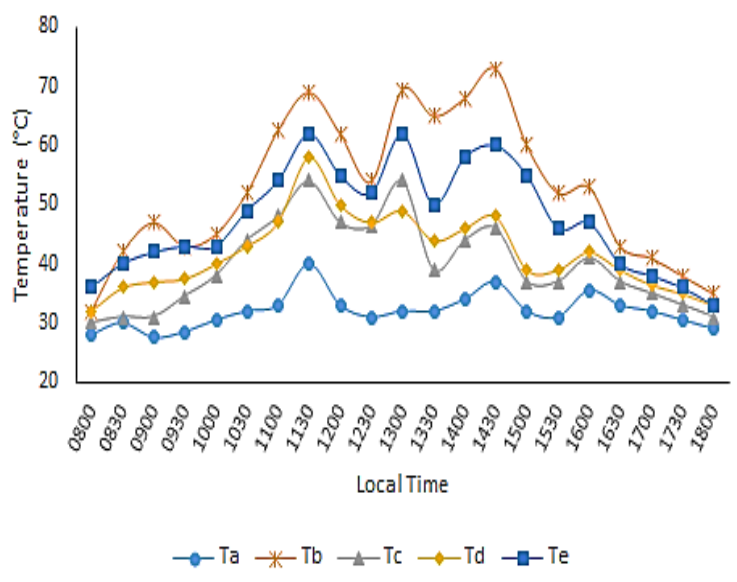

(c)

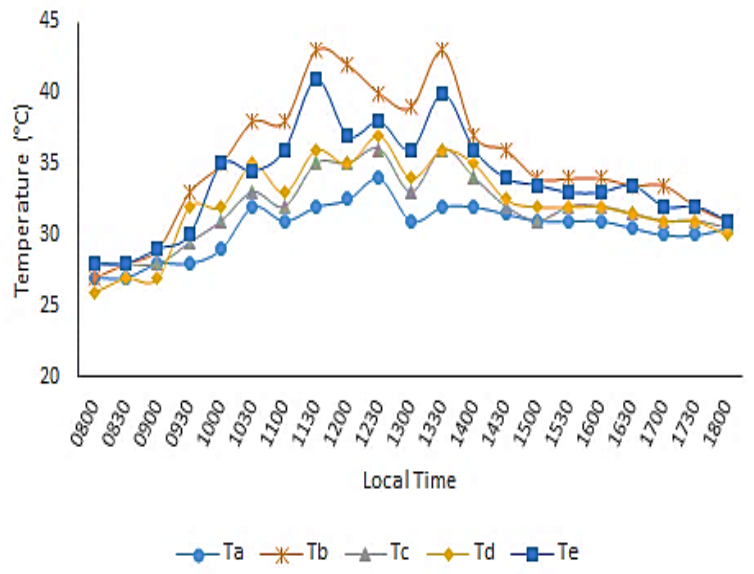

Fig. 3 Temperatures measured in the solar dryer on (a) day 1 , (b) day 2 , (c) day 3.
The highest temperatures reached were $58^{\circ} \mathrm{C}$ and $54^{\circ} \mathrm{C}$ at the middle and lower tray respectively. It was noticed that the fluctuations in ambient temperature, resulting from the periodically cloudy weather conditions, significantly affected the temperatures recorded in the solar dryer. At cloudy periods, the temperature within the solar dryer drops just as the ambient temperature drops. Fluctuations in weather conditions were observed throughout the period of testing as typified in Fig. 3a-c. The elevated temperature within the dryer shows the solar dryer had potential for better drying compared to open air drying.

Fig. 4 shows the moisture content of agricultural products within the solar dryer within the period of drying for tomato, okra and pepper. Fig. 5 shows the drying rate of the tomato, okra and pepper obtained during drying on different days. It is seen that the moisture loss and drying rate is highest in tomato compared to pepper and okra. The reason is because of the reduction in the size of tomato slices compared to okra and pepper which increases the surface area and consequently the drying rate.

From Fig. 5, it is observed that the highest drying rate of samples considered occurs between 1200 hours and 1400 hours. Comparing with Fig. 3, it is seen that the period with the highest drying rate coincides with when the temperature within the dryer is at its peak. This implies that the temperature within the solar dryer influences the drying rate of the agricultural products. Hence, if the temperature within the solar dryer could be maintained, a nearly constant drying rate could be achieved. Methods of achieving this include the use heat storing materials as part of fabrication materials of the solar dryer and utilizing an alternative source of energy (possibly biomass heating) to heat the air which enters into the drying chamber.

During the drying process, it was observed that the slowest drying rate occurred at the lowest tray, away from the air inlet from the auxiliary heater. This is due to the poor flow of air within the solar dryer operating in natural draft which had caused insufficient air flow across the products in that section of the solar dryer. This may be solved by the utilization of a blower or fan to force warm air into the solar dryer and cause a better of air flow for effective drying. 


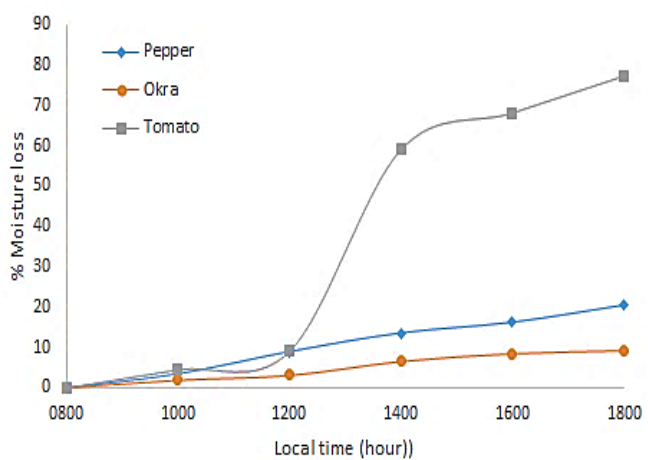

Fig. 4 Percentage moisture loss of samples of pepper, okra and tomato in the solar dryer

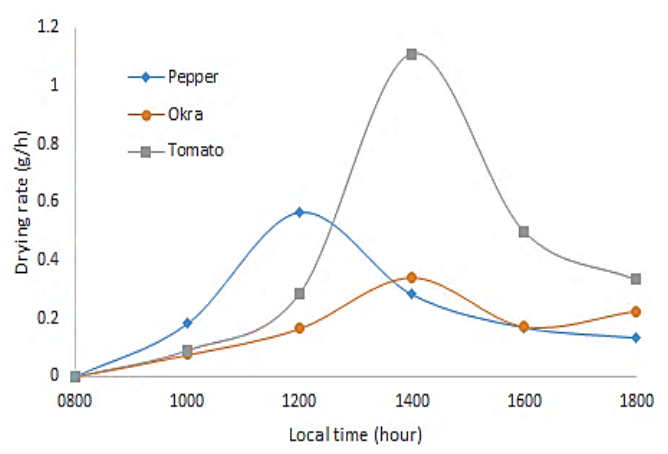

Fig. 5 Average drying rate of samples of pepper, okra and tomato in the solar dryer

Taking the specific latent heat of water as $2264.8 \mathrm{~kJ} / \mathrm{kg}$, specific heat capacity of air at constant pressure, $c_{p}$, as $1.0 \mathrm{~kJ} / \mathrm{kgK}$, density of air as $1.0 \mathrm{~kg} / \mathrm{m}^{3}$, and the air flow rate as 0.03 $\mathrm{m}^{3} / \mathrm{s}$, the solar collector efficiency is estimated to be $52 \%$ and the average drying efficiency during the period was $21.9 \%$. The drying efficiency is in the range of efficiencies reported in literature $[5,11,12,22]$.

\section{Conclusion}

In this study, a natural draft mixed-type solar dryer was developed and evaluated. The dryer was used to dry some agricultural products (tomato, pepper and okra). The temperatures measured at different points of the drying chamber and the auxiliary collector show that the temperatures within the drying chamber were higher than the ambient temperature. The temperature within the drying chamber was also found to depend on the atmospheric conditions and also varies with the ambient temperature. The drying rate and moisture content of the agricultural products in the solar dryer were determined at intervals. The maximum drying rate was observed at periods between 1200 and $1400 \mathrm{hrs}$ local time which corresponds with the period when the temperature within the solar dryer is maximum. The solar collector efficiency was $52.0 \%$ while the drying efficiency was $21.9 \%$. Further work to improve the efficiency and performance of the solar dryer should incorporate a fan or blower which would aid better air circulation within the dryer. Using heat storing materials as part of fabrication materials of the solar dryer and utilizing an alternative source of energy to heat the air which enters into the drying chamber should also be explored.

\section{References}

[1] Markus, H. and Albert, E. (1996). "Evaluation of the drying efficiency of solar cabinet dryer using okra", Nigerian Journal of Solar Energy, Vol. 19, No. 1, p. 6.

[2] Chaudhari, A.D. and Salve, S.P. (2014). "A review of solar dryer technologies", International Journal of Research in Advent Technology, Vol. 2, No. 2, pp. 218232.

[3] Weiss, W. and Buchinger, J. (2001). Solar Drying. Training course within the scope of the project: Establishment of a production, sales and consulting infrastructure for solar thermal plants in Zimbabwe, Austrian Development Cooperation.

[4] Mühlbauer, W. and Esper, A. (1999). Solar Energy. CIGR Handbook of Agricultural Engineering, Volume V - Energy and Biomass Engineering, Chapter 2.3, Kitani, O. (Ed.), American Society of Agricultural Engineers, USA.

[5] Lawrence, D., Folayan, C.O. and Pam, G.Y. (2013). "Design, construction and performance evaluation of a mixed-mode solar dryer", The International Journal of Engineering and Science (IJES), Vol. 2, No. 8, pp. 8-16.

[6] Foster, S.A. (2013). Construction and performance testing of a solar food dryer for use in developing countries, Master of 
Science Thesis, Brigham Young University, Provo.

[7] Umogbai, V.I. and Iorter, H.A. (2013). "Design, construction and performance evaluation of a passive solar dryer for maize cobs", African Journal of Food Science and Technology, Vol. 4, No. 5, pp. 110-115.

[8] Abdullahi, A.F. (2007). Development and performance evaluation of an on-farm forced convection solar dryer for tomato. Master of Science Thesis, Amadu Bello University, Zaria, Nigeria.

[9] Raju, R.V.S., Reddy, R.M. and Reddy, E.S. (2013). "Design and fabrication of efficient solar dryer", International Journal of Engineering Research and Applications, Vol. 3, No. 6, pp. 14451458.

[10] Gavhale, M., Kawale, S., Nagpure, R., Mujbaile, V.N. and Sawarkar, N.S. (2015). "Design and development of solar seed dryer", International Journal of Innovative Science, Engineering and Technology, Vol. 2, No. 4, pp. 1005-1010.

[11] Eke, B.A. (2013). "Development of small scale direct mode natural convection solar dryer for tomato, okra and carrot", International Journal of Engineering and Technology, Vol. 3, No. 2, pp. 199-204.

[12] Bolaji, B.O. and Olalusi, A.P. (2008). "Performance of a mixed-mode solar dryer", AU Journal of Technology, Vol. 11, No. 4, pp. 225-231.

[13] Akoy, E.O.M., Ismail, M.A., Ahmed, E.A. and Luecke, W. (2006). "Design and construction of a solar dryer for mango slices", Proceedings of International Research on Food Security, Natural Resource Management and Rural Development-Tropentag. University of Bonn, Bonn, Germany.

[14] Ezekoye, B.A. and Enebe, O.M. (2006). "Development and performance evaluation of modified integrated passive solar grain dryer", The Pacific Journal of Science and Technology, Vol. 7, No. 2, pp.185-190.
[15] Bharadwaz, K., Barman, D., Bhowmik, D. and Ahmed, Z. (2017). "Design, fabrication and performance evaluation of an indirect solar dryer for drying agricultural products", International Research Journal of Engineering and Technology, Vol. 4, No. 7, pp. 1684-1692.

[16] Lingayat, A., Chandramohan, V.P. and Raju, V.R.K. (2017). "Design, development and performance of indirect type solar dryer for banana drying", Energy Procedia, Vol. 109, pp. 409-416.

[17] Ehiem, J.C., Irtwange, S.V. and Obetta, S E. (2009). "Design and development of an industrial fruit and vegetable dryer", Research Journal of Applied Sciences, Engineering and Technology, Vol. 1, No. 2, pp. 44-53.

[18] Duffle, J.A. and Bechman, W.A. (1991). Solar engineering of thermal processes. Second edition, Wiley Interscience, New York.

[19] Orisaleye, J.I., Ismail, S.O., Ogbonnaya, M. and Ogundare, A.A. (2018). "Development and performance evaluation of a solar water still", Acta Technica Corvininesis-Bulletin of Engineering, Vol. 11, No. 1, pp. 91-96.

[20] Energy Commission of Nigeria (ECN) and United Nations Development Programme (UNDP) (2005). Renewable Energy Master Plan (REMP). Final Report, November 2005.

[21] Bureau of Energy Efficiency, BEE (2004). Energy efficiency guide book. Chapter 5, Bureau of Energy Efficiency, India, pp. 93-112.

[22] Schiavone, D.F. (2011). Development and evaluation of natural-convection solar dryer for mango in rural Haitian communities. Master of Science Thesis, University of Florida. 